\title{
GLOBALIZAÇÃO E A MUDANÇA DO PAPEL DA UNIVERSIDADE FEDERAL BRASILEIRA: UMA PERSPECTIVA DA ECONOMIA POLÍTICA
}

\author{
João dos Reis Silva Júnior \\ Eric Spears ${ }^{* *}$
}

\begin{abstract}
"Any discussion related to global (...) academic mobility must be seen in the context of the current worldwide financial crisis." "*** (Willian L. Gertz, American Institute For Foreign Study)
\end{abstract}

\begin{abstract}
RESUMO
A proposta deste artigo é analisar a atual fase de internacionalização da educação superior e suas consequiências para este setor social no Brasil, considerando a hipótese de que este processo ocorrido em outros momentos da história da educação brasileira orientava-se predominantemente por demandas acadêmicas dos alunos e professores, mas, na atualidade, em face da globalização da economia capitalista, o que assistimos é uma globalização da educação superior pública motivada por demanda econômica e parte da globalização da economia com consequiências o seu papel sócio-econômico e pelo estabelecimento de uma hierarquia das áreas do conhecimento orientada pela globalização do capital financeiro.

Palavras-chave: Mobilidade acadêmica; globalização da educação superior pública; mercantilização da educação superior; globalização da economia.

\section{GLOBALIZATION AND CHANGING ROLE OF BRAZILIAN FEDERAL UNIVERSITY: A PERSPECTIVE OF POLITICAL ECONOMY}

\section{ABSTRACT}

The article's purpose is to analyze the current phase of internationalization of higher education and its consequences for the social sector in the Brazil, regarding the hypothesis that this process occurred at other times in the history of Brazilian education directed predominantly by academic demands of students and professors, but, today, facing globalization of the capitalist economy, what we are witnessing is a public higher education globalization motivated by economic demand and part of the globalization of the economy with the consequences their socio-economic role and the establishment of a hierarchy of areas of knowledge driven by the globalization of finance capital.

Keywords: Academic Mobility; globalization of public higher education; commodification of higher education; economic globalization.

\section{Introdução}

Na economia marcada pela mundialização do capital sob a predominância financeira, a cultura da universidade pública põe-se em uma decadente travessia de significativa mudança, observável em muitos outros países em âmbito planetário. A instituição federal de ensino superior (IFES) brasileira está mais suscetível às ações do 
Estado neste contexto. De maneira geral, as universidades estão deixando de ser locais de conhecimento construído com base em estudos clássicos (ex. Humanidades) para desenvolver produtos de educação que atendam as demandas do Mercado global (ex. Ciências aplicadas e vários tipos de programas de Master Business Administration (MBA). (Newman e Couturier, 2001)

Embora este processo apresente oportunidades para o desenvolvimento de projetos empreendedores e de inovação tecnológica, sua dimensão econômica também desestabiliza a autonomia acadêmica e institucional em nível local. Este desafio pode ser observado no Brasil, onde a economia do século XXI está reorganizando, de forma predominante, a educação superior para ciências aplicadas orientadas para a ciência, tecnologia e inovação como um trinômio indissociado e guiado pela economia.

A orientação para a pesquisa aplicada impregnou as administrações das universidades brasileiras por forte competição, levando pesquisadores e estudantes a competirem uns contra os outros, como consequiência da tentativa imposta pelo Estado de igualar o tempo econômico ao tempo de criação acadêmico-científico. Embora a competição acadêmica por concessão de recursos financeiros seja o padrão na maioria dos países, essa transição tem ocorrido de maneira muito rápida no sistema federal de ensino superior brasileiro, gerando resistência por parte dos acadêmicos. Segundo Gürüz, a educação superior entrou em uma era em que foram iniciados processos para transformá-la de um setor público estruturado e regulado pelo governo para um setor semi-público a fim de responder a demanda e a competição econômica. Esse processo continua até o presente momento. (Gürüz, 41, 2011) Certamente, este é o caso do Brasil. A tensão entre Estado e o livre Mercado, foi reconhecida há um quarto de século atrás pela economista, Susan Strange, em seu livro "Estados e Mercados (1988)", que o nexo da autoridade de Mercado, ou melhor, a autoridade competitiva entre Mercado e Estado abriu uma perigosa lacuna de instabilidade social, econômica e política.

$\mathrm{O}$ fato de o capitalismo influenciar a organização territorial do Estado é bem documentado (Smith, 1984; Harvey, 1996; Swyngedouw, 1997) e seus efeitos recentes sobre a organização do sistema universitário federal brasileiro demonstram ainda mais como o capital encontra um território inexplorado, com a retirada do Estado deste espaço público, deixando-o como um excelente espaço de produção real de valor. Em face do modelo econômico adotado no início da década de 1990 as demandas para a transformação da República Federativa do Brasil foi intensa.

As ambições capitalistas do Brasil, no contexto da economia mundialziada, não levaram somente a competição entre docentes e entre estudantes, mas estão incorporadas na política externa, como demonstrado no programa Ciências Sem Fronteiras ou no Programa Nacional de Pós-Doutoramento (PNPD) lançado quando da realização da IV Conferência Nacional de Ciência Tecnologia e Inovação. Evento de magnitude social, econômica e política, quando a Política de C\&T\&I foi alçada à Política de Estado em vez de governo. A mobilidade acadêmica brasileira tem demonstrado por meio destes e outros programas financiados pelo governo o grau em que algumas disciplinas específicas são reconhecidas como mais estratégicas do que outras. Esse dado pode argumentativamente sugerir que a tendência na educação superior brasileira é similar aos demais países emergentes do BRIC (Brasil, Rússia, Índia e China), aos tigres asiáticos (Coréia do Sul, Taiwan e Singapura) e aos novos pontos de globalização (Dubai, África do Sul e Malásia).

O setor privado de educação do Brasil também tem desempenhado um papel fundamental. Por outro lado a universidade federal responde com mudanças estruturais ao capitalismo. Wildavsky argumenta que a globalização da pesquisa tradicional tem sido um fenômeno da elite. Ela abriu um nicho para escolas com fins lucrativos, tendo como alvo 
um segmento demográfico de estudantes não pertencentes à elite. (Wildavsky, 2010, 142) A estrutura tradicional do sistema federal universitário brasileiro com o seu Exame Nacional de Ensino Médio (ENEM) para admissão busca garantir, sem êxito até o momento, uma boa educação pública aos mais qualificados, contudo esse direito tornou-se mais um privilégio. Os alunos das escolas de ensino médio privadas mais elitistas são mais bem classificados do que aqueles provenientes de um sistema público de ensino desigual.

A globalização é uma aposta e a entrada do Brasil no capitalismo do século XXI, guiado pelo Consenso de Washington gerou um movimento instável na política econômica brasileira. Atualmente, o Brasil é um país com uma economia pujante, e emergente o que lhe confere a sexta posição no ranking mundial. A sua análise requer uma síntese sob diferentes perspectivas e tradições acadêmicas. A competição econômica na globalização impulsiona o desenvolvimento industrial, a urbanização e mudanças demográficas em cada país. Neil Smith (1984) reconheceu a capacidade global do capitalismo há aproximadamente três décadas atrás com sua publicação de Uneven Development. Em seu livro Neil Smith examina novas formas de industrialização, desindustrialização, declínio regional, urbanização, geopolítica, nacionalismo e a divisão internacional do trabalho. Smith escreve que os processos de globalização "não são desenvolvimentos separados, mas sintomas de uma transformação mais profunda na geografia do capitalismo". (Smith, 1984: I) A premissa de Smith sobre a economia global permanece ainda mais evidente trinta anos depois. No entanto, a perspectiva atual de educação internacional oferece poucos subsídios para uma compreensão sistêmica da maneira pela qual o capitalismo organiza e utiliza o ensino superior como meio de produção em nível mundial e local. Essa dialética é encontrada nas universidades, tanto públicas quanto privadas, em todo o Brasil e em outras partes do globo, norte e sul. O objetivo deste artigo é, portanto, buscar compreender as mudanças na universidade pública no Brasil, com ênfase nas IFES na sua relação com o processo de internacionalização deste nível educacional que parece encontrar-se em todo o planeta. Procuramos explicar a forma como a mercantilização da educação brasileira é um indicativo de forças da globalização da economia e da predominância do capital financeiro. Utilizamos a universidade federal brasileira como um exemplo desta mercantilização do ensino superior em razão de sua proximidade e dependência próxima das decisões do governo central. Em particular, defendemos que o ensino superior brasileiro está sendo socialmente reorganizado como uma mercadoria (a exemplo de bens, serviços e produtos financeiros) que atendem as demandas da economia política global contemporânea, definindo áreas de conhecimento prioritárias pelo governo federal brasileiro com valores de mercado diferentes, mas, de acordo com o seu valor estratégico e percebido. Essa percepção de valor é o resultado da nova divisão do trabalho no contexto da globalização econômica. O ex-presidente Fernando Henrique Cardoso (2001), talvez, elucide esta transformação global da universidade brasileira, da seguinte forma. Ele escreve, "o mundo mudou, a natureza do Capital mudou, a natureza do trabalho também mudou. Os instrumentos necessários para alcançar níveis crescentes de inclusão social foram igualmente alterados" (CARDOSO, 2001, 258).

\section{Brasil na Economia Política Global}

A economia política brasileira contemporânea é muito diferente dos dias de ditadura militar e do "milagre econômico brasileiro" do início dos anos 1970". A economia política brasileira atual realinhou o ensino superior vis-à-vis ao lugar que o país passou a ocupar na atual divisão internacional do trabalho e o novo papel que é imposto às universidades públicas. A economia atual é de fato muito diferente da década de 1980 e 
início de 1990, quando o Brasil enfrentou uma série de crises econômicas e implementou programas de reestruturação que tiveram origem tanto dentro como fora do país. A dívida brasileira, a hiperinflação e a corrupção prejudicaram o crescimento econômico. Desde sua criação na década de 1950, as universidades federais não interagiam com a economia neoliberal global moderna. ${ }^{2} \mathrm{O}$ Brasil permaneceu dependente das trocas internacionais de produtos primários e commodities. As reservas brasileiras de produtos primários e commodities, tais como cana-de-açúcar, café e diferentes tipos de energia, foram considerados fundamentais na pauta de exportação, enquanto os serviços de ensino nas universidades públicas (e, em certa medida, as universidades privadas) mantiveram-se em uma bolha autônoma e com financiamento público. $\mathrm{O}$ ensino superior, em especial o público, sofreu poucas alterações, entre as décadas de 1970 e 1990, como resultado da economia arruinada. ${ }^{3}$

O Brasil encontrou um crescimento sem precedentes de 7,5\% em 2010 (Departamento de Comércio dos EUA, 2010) e, apesar das projeções para 2013 mostrarem um declínio para cerca de 3\%, o país sul-americano continua bem posicionado na economia global. Enquanto os Estados Unidos tem um superávit comercial de US\$ 7 bilhões, o Brasil ainda exportou US\$ 30,4 bilhões em produtos para o seu parceiro do norte. A produção de energia, através de petróleo e etanol de cana de açúcar, tornou-se uma atividade econômica fundamental, destacando-se estes dois setores primários e secundários da economia.

Além disso, o Brasil obteve um superávit comercial no setor de serviços com os Estados Unidos, totalizando US\$ 13,4 bilhões em 2010. Estes serviços incluem educação superior, que compreende uma parte importante do Brasil, de US\$ 6,5 bilhões em divisas recebidas dos Estados Unidos pelo comércio de educação, serviços financeiros, seguros, telecomunicações, profissionais, empresariais e de serviços técnicos (Comissão de Comércio Internacional dos EUA, 2012). Esta expansão econômica é oportuna para empresas, empresários e políticos, mas também possibilita nova pressão sobre a universidade federal para produzir novas formas de inovação, pesquisa, além de intensificar o trabalho docente e induzir a precariedade de suas relações.

Além disso, há uma pressão para o estabelecimento de novas formas de trabalho condicionado pelo aumento do desemprego em todo o Brasil. A população jovem do Brasil entre 14 e 21 anos de idade sofre de uma taxa de $17 \%$ de desemprego, que afeta de forma desproporcional mais as mulheres do que os homens (13\% dos jovens estão desempregados e $23 \%$ das mulheres jovens estão sem trabalho). A população brasileira (205.716.890 com uma taxa de crescimento de cerca de $1 \%)$ tem uma média de idade de 29,3 anos (28,5 anos em homens e mulheres de 30,1 anos) (IBGE, 2012) Esta concentração de mão de obra é mais pronunciada nas cidades brasileiras, onde a taxa de urbanização é de $87 \%$ - tornando o país um das sociedades urbanas mais densamente povoadas (IBGE, 2012).

O PIB per capita do Brasil é de US $\$ 11.900$ sendo o desemprego muito mais alto em jovens e adultos jovens. No entanto, o Brasil ainda é classificado como sexto maior mercado de trabalho do mundo. A maioria do emprego (67\%) concentra-se no setor de serviços (serviços financeiros e outras atividades terciárias); a indústria ocupa o segundo lugar $(27,5 \%)$ e a agricultura está posicionada no terceiro lugar (5,5\%) (IBGE, 2012). O setor de serviços também pressiona a universidade federal brasileira para a formação de profissionais para mercado de trabalho em carreiras exercidas em empresas.

No entanto, o Brasil continua sendo um país de desenvolvimento desigual, com concentrações excessivas em cidades do Sudeste, bem como infra-estrutura, serviços e população. A divisão entre as esferas urbanas e rurais é impressionante, mas o fosso entre 
os "que têm" e "os que não têm" nas áreas urbanas é demarcada ainda mais acentuadamente no mapa social. As melhorias com o objetivo de amenizar a pobreza crônica no Brasil têm resultados mistos. Por exemplo, o programa Bolsa Família lançado pelo governo Lula no início de 2000 elevou os rendimentos da população de baixa renda, mas fez muito pouco para resolver os problemas sistêmicos que minam capital coletivo social do Brasil ${ }^{4}$. As despesas públicas em educação são ainda menor do que em outros dez maiores países econômicos (5 por cento do PIB, classificados 55 no mundo) - UNSD (2012). As tentativas mais recentes de integrar uma população muito heterogênea nas universidades mais competitivas e públicas com políticas de ação afirmativa também têm exposto a desigualdade social e racial na América Latina.

O programa Bolsa Família foi reconhecido pelo governo federal brasileiro e de outros grupos de reflexão (por exemplo, a Fundação Getúlio Vargas - FGV) como um instrumento para redução da pobreza, $27 \%$ ao longo de uma década. Este aumento de uma classe média baixa tem fomentado o crescimento do nicho de mercado das universidades com fins lucrativos no Brasil que oferecem cursos em áreas técnicas para atender às necessidades de um mercado em expansão. O ensino superior brasileiro, tanto na esfera privada como pública, é reconhecido pelo Estado brasileiro como parte de uma estratégia de longo prazo de hegemonia na América do Sul. O ensino superior também é romantizado em seu objetivo de ascensão social, amenizando as estruturais desigualdades sociais no Brasil. Paradoxalmente, no entanto, o ensino privado atrai aqueles alunos que não conseguem passar no vestibular da Universidade Pública Federal (geralmente classe média baixa) e, o sistema público e gratuito continua a ser aquele que aceita os alunos de elite do país (a maioria dos quais oriundos de escolas particulares). Essa dialética entre as esferas pública e privada na educação desafia a axiologia tradicional das humanidades e ciências sociais à luz de um reducionismo aplicado à aprendizagem e ao currículo, que visam à formação prática em determinadas carreiras com base numa epistemologia da prática.

A reestruturação econômica e o novo papel da universidade pública no crescimento econômico nacional evoluíram em conjunto. Deliberados planos nacionais de reestruturação econômica e outras escolhas políticas feitas pela liderança do Brasil no início de 1990 colocaram a universidade brasileira numa nova trajetória de reformas irreversíveis. Os ex-presidentes Fernando Henrique Cardoso (1995-2002), Luiz Inácio Lula da Silva (2003-2010), e a atual Dilma Rousseff (2011 - Presente) têm olhado para a universidade brasileira como de importância estratégica e meio para crescimento econômico ${ }^{5}$. O Plano Real estabeleceu uma economia mais estável no Brasil possibilitando a privatização, a expansão da classe média e a inovação ${ }^{6}$. As universidades públicas foram reformuladas para se tornar os pivôs da expansão econômica brasileira, porém ao lado da oportunidade acadêmica existe a pressão para inovar e contribuir para o crescimento econômico a curto e médio prazo.

Os intelectuais críticos brasileiros, no entanto, perceberam no Plano Real mais do que uma estratégia eleitoral. De fato entenderam que o plano era o instrumento de ajuste estrutural da economia brasileira. Fiori (1995), por exemplo, demonstra que o Plano Real surgiu a partir de um conjunto de recomendações feitas pelo Consenso de Washington. $\mathrm{O}$ Consenso de Washington destacou as reformas macroeconômicas, a privatização de empresas estatais e a liberalização do comércio na América Latina em todo o mundo atingindo algo aproximado de sessenta países. Os economistas que representaram o Brasil no Consenso de Washington (Edmar Bacha, Pérsio Arida, Gustavo Franco, Pedro Malan) mais tarde tornaram-se membros do núcleo da equipe econômica do presidente Fernando 
Henrique Cardoso. A estes indivíduos foi creditada a incorporaração das idéias neoliberais à nova economia brasileira.

Fiori (1995) argumenta que o Plano Real foi uma iniciativa que não poderia ter sido politicamente viável até a eleição do presidente Fernando Henrique Cardoso em 1994. Reformas econômicas foram recomendadas pelo Consenso de Washington no início de 1990, mas o turbulento governo de Fernando Collor de Mello ${ }^{7}$ (1990-1992) impediu que ocorresse qualquer reforma econômica significativa. O Brasil não realizou a reforma econômica até Fernando Henrique Cardoso que se tornou ministro das finanças de 1993 1994 na administração de Itamar Franco que ocupou o cargo após a renúncia de Collor de Mello. Cardoso posteriormente elegeu-se presidente em 1994 e lançou o Plano Real, em concordância temporal com a fase mais recente da mundialização do capital.

O conjunto de reformas institucionais implementado pelo Plano Real, estabeleceu um ambiente favorável a empreendimentos público-privado dentro do aparelho de Estado. Cardoso (2001) fornece a razões para esta nova abordagem na governança. Ele escreve: "... neste sentido, a reforma do Estado prevê incentivos para a racionalização formal da máquina pública e os critérios de concorrência aberta, em detrimento dos poderosos registros burocráticos" (Cardoso, 2001: 212). Essa mentalidade política em Brasília orientou a reforma e a internacionalização da universidade federal no início de 2000 , que reflete a seguinte racionalidade, conforme descrito por Childress: promover a mudança econômica, política e sócio-cultural. (Childress, 2010: 10).

\section{Consequências para a Universidade Pública brasileira}

O presidente FHC, que em sua trajetória acumulara sólido capital acadêmico e político tornou-se uma âncora política e cultural para uma forte aliança que pudesse dar sustentação ao estrutural Plano Real. Esta aliança política deu a FHC a condução para implantar o audacioso e estrutural Plano que produziria a aderência do Brasil à predominância financeira. Contudo, o plano tornou-se o próprio programa de governo dos dois mandatos de FHC e reestruturou os fundamentos da economia do país, que exigiu a estrutural mudança das instituições republicanas do país.

O Plano Diretor da Reforma do Aparelho do Estado de 1995 foi formulado na administração de Fernando Henrique Cardoso como um meio de fomentar empreendimentos públicos e privados no Brasil. O exemplo mais conhecido desta fase da privatização é a empresa estatal Companhia Vale do Rio Doce, que é a maior produtora mundial de minério de ferro. Outros exemplos de privatização das indústrias estatais incluem as telecomunicações na década de 1990. Segundo Melo, Gaetani, Pereira (2005), o surgimento e a consolidação de mercados globais em domínios como as telecomunicações sugeriu que as soluções nacionais baseados em empresas privadas nacionais ou monopólios de Estado já não eram soluções viáveis ${ }^{8}$.

O Plano Diretor da Reforma do Aparelho do Estado estabeleceu um novo precedente para as parcerias público-privadas na educação superior brasileira, o que impulsionou o país rumo a um Estado marcado pela racionalidade econômica, alterando as esferas públicas e privadas. Este movimento institucional afeta de pronto as universidades públicas, enfaticamente a universidade federal. Parafraseando Harvey, as universidades passam a ter um papel de "activista em criar um bom clima de negócios e a se comportar como uma entidade concorrencial na política global" (Harvey, 2005: 79). A adoção de um modelo com maiores facilidades para o planejamento estratégico no final da década de 1990 e início da de 1990 consolidou uma cultura institucional que estruturou de uma vez a importância das parcerias público-privadas (PPP) ${ }^{9}$. 


\section{Fases da Educação Superior Brasileira}

Há cerca de duas décadas assiste-se no Brasil a uma lenta e profunda mudança na cultura institucional da universidade pública, resultado das opções político-econômicas deliberada e conscientemente assumidas pelos governos Fernando Henrique Cardoso FHC (1995-2002), Luiz Inácio Lula da Silva - LULA (2003-2010) e Dilma Rousseff DILMA (2011-2014). Sobre as raízes desse processo é possível propor algumas hipóteses e demarcar, de forma nítida, alguns períodos que o compuseram ao longo do tempo.

Ao adotarmos uma subdivisão deste largo período em três etapas, entendemos que a primeira se constituiu na série de reformas institucionais, com início e expressão máxima na reforma do Aparelho do Estado levada a termo durante os governos FHC e liderada pelo Ministério da Administração Federal e da Reforma do Estado (MARE), em que os governantes brasileiros iniciaram o pretendido alinhamento do país à transição em curso em nível mundial. Nessa fase o processo é institucionalizado, uma vez que muitas tentativas já haviam sido feitas durante a década de 1980. O capitalismo experimentava nesse período a transição de um Regime de Acumulação Monopolista para um Regime de Acumulação de Predominância Financeira, tendo provocado significativa ruptura na história recente do país.

Desta reforma - matriz decorreram outras, que alcançaram, mas não de modo imediato, as mais diversas instâncias, órgãos estatais e instituições republicanas em geral e, em particular, a instituição universitária pública. Dentre os traços característicos dessa cultura institucional universitária, destacam-se: a pesquisa aplicada; os cursos aligeirados oferecidos mediante modalidades educacionais apoiadas em novas tecnologias de informação e comunicação; os processos avaliativos ou de regulação e controle externos; a gradativa perda da autonomia universitária, indissociada da emergência de uma heteronomia de gestão e de uma nova relação entre universidade e setor empresarial, sob a indução e o apoio do governo, tal como há tempos já se observava nos países de economia central, cuja acentuação ocorreu no caso da União Européia, especialmente com o Processo de Bolonha. Esta segunda fase encontra-se relacionada, com maior proximidade, ao período dos governos de LULA, embora dê continuidade às reformas da primeira fase implementadas nos governos FHC.

Todavia, ainda na gestão de LULA, é possível apontar um terceiro momento desse processo de mudanças na universidade pública, marcado pela emergência de programas com forte potência de mudança institucional, como o Programa de Apoio ao Plano de Reestruturação e Expansão das Universidades Federais (REUNI), a Educação a Distância (EAD), a Universidade Aberta do Brasil (UAB), a continuidade da expansão da pósgraduação - ainda que de forma atenuada, em relação a momentos anteriores - e da respectiva indução da pesquisa ali desenvolvida. Quanto à pós-graduação, a partir de 2007 e, de modo contínuo, aos dias atuais, tais processos se solidificaram e, em consequência, intensificou-se o trabalho do professor da universidade pública. O trabalho se reestrutura, especialmente em relação ao modo de fazer científico, exigindo reduzido tempo de investigação e resultados efêmeros face ao novo paradigma de ciência hoje demandado. Destaca-se, nesta fase, uma expansão de matrículas algo anômala da educação superior pública no país, mormente no setor das Federais, em nível da graduação, como se pôde verificar ao final do governo LULA.

Este movimento desdobra-se em duas largas dimensões concomitantes: a continuidade do processo de mercantilização da produção do conhecimento e a certificação 
em massa dos estudantes de graduação e de pós-graduação, sendo que cada um desses níveis qualifica mão de obra destinada a diferentes patamares da economia. Estas duas dimensões constituem-se em pólos opostos e complementares: a certificação em massa em nível de graduação e de pós-graduação lato sensu está, em geral, direcionada às grandes parcelas da sociedade mais excluídas, para atuarem nos espaços empresariais de maior exploração e menor exigência técnica. Por sua vez, a certificação, especialmente no âmbito da pós-graduação stricto sensu (mestrado e doutorado), e a pesquisa, predominantemente aplicada, tendem a colocar-se a serviço do setor empresarial nacional e internacional, com grau de menor exploração e maior exigência técnica, no caso da formação profissional, ao mesmo tempo em que, no caso da pesquisa, denota o acúmulo de conhecimento que o país alcançou e busca ampliar de forma induzida. Esta dimensão se direciona aos melhores alunos das universidades melhor avaliadas (ou reguladas) por órgãos governamentais com essa função e por critérios produzidos no âmbito do Estado. A partir dos números sobre a universidade pública no Brasil, que adiante serão vistos, é possível afirmar que nas últimas duas décadas esta se transformou em um movimento que tem avançado a conta-gotas, com raros momentos mais significativos como, por exemplo, o REUNI. ${ }^{10}$

De acordo com os dados da Pesquisa Nacional por Amostra de Domicílios 2009 (PNAD, 2010), com referência à relação entre escolarização e renda familiar, as Regiões Norte e Nordeste apresentam os piores índices em termos de defasagem educacional de alunos pobres, com idade entre 15 e 24 anos - em termos percentuais, o total de alunos que cursam o ensino médio na Região Norte atinge a 45\%, enquanto que na Região Nordeste, $41 \%$. Estes índices, quando comparados à Região Sudeste, com aproximadamente 60,5\% para a mesma faixa etária, indicam a desigualdade entre os estados da federação brasileira que se encontram distantes ou próximos dos centros econômico-político-sociais hegemônicos. Esta observação nos remete a outro problema estrutural já apontado na literatura econômica: o entendimento do Brasil impõe considerar as desigualdades regionais produzidas pelo desenvolvimento histórico do capitalismo no país. (TAVARES, 1997).

No final dos anos 1980 e início dos 1990 era possível afirmar, não sem algum grau de idealização, que o centro da cultura da universidade pública apresentava-se na forma de uma contradição clássica: por um lado, ela contribuía para o crescimento econômico do país e para a consolidação do pacto social de então; por outro, punha-se como o lugar institucional da crítica de seu tempo histórico e de seus próprios objetivos. Tratava-se, de maneira distinta do que ocorre nas igrejas, que se fundamentam no dogma, de ver a universidade como espaço saudável e necessário da dúvida, da crítica e do debate. Ao longo do período que desde então decorreu, enquanto o primeiro pólo haveria de sofrer clara hipertrofia, teria havido uma significativa atrofia histórica do segundo. A crítica e o debate deram lugar ao silêncio e ao apoio, com raras exceções, aos planos, programas e atividades oficiais, sugerindo que a instituição republicana universitária tenha se convertido em agência executora bastante acrítica de políticas públicas de competência do Estado. De forma mais precisa, a universidade pública, assim como o Estado, tornou-se instrumento, ainda que indireto, de produção enquanto o país, com uma economia com alta capacidade de acumulação e plena disponibilidade de importantes recursos do fundo público estatal, tornou-se porto seguro para o mercado mundial de capitais industriais e financeiros. A universidade pública alterou radicalmente sua cultura institucional ao passar por tais mudanças de perfil e características quando o país se alinhou, com FHC na presidência, ao regime de predominância financeira. Isto explicaria, entendemos, o essencial de sua mudança ao longo das duas últimas décadas. 
Nas páginas a seguir procuraremos explicar como tem se dado a expansão da educação superior pública nas últimas décadas, com anômala aceleração no setor das instituições federais desde a implantação do REUNI, da EAD, via UAB, assim como apresentar argumentos que contribuam para se verificar as hipóteses a respeito das razões dessa expansão e da expansão da graduação, da pós-graduação e da pesquisa nas esferas pública e privada, concomitantemente com as mudanças estruturais na cultura institucional universitária a que se fez breve referência nas linhas anteriores.

\section{V - A expansão da educação superior brasileira}

Segundo a Sinopse Estatística da Educação Superior (2011), pode-se afirmar que no primeiro mandato de FHC as políticas públicas induziram o crescimento do número de instituições de forma lenta, a pequenas taxas de incremento. Contudo, observa-se que o número das IES públicas reduziu-se em aproximadamente $4 \%$, enquanto a porcentagem deste crecimento no setor privado oscilou em torno de $20 \%$. Na década de 1980, as matrículas aumentaram cerca de dez vezes se comparadas ao início da ditadura civilmilitar, nos anos 1960. Nos governos FHC houve expansão na área privada, embora ainda menor que durante o período ditatorial, porém com um crescimento duas vezes maior que no setor público. $\mathrm{O}$ setor privado experimentou um grande incremento, em especial no segundo mandato de FHC (1999-2002), depois de aprovada a Lei de Diretrizes e Bases da Educação Nacional. Sugerimos a hipótese segundo a qual os empresários da educação esperaram a promulgação da legislação federal para investirem com seguramça o capital de serviços nacional e internacional.

[...] Pode-se verificar um aumento no número de instituições públicas e privadas de cerca de 50\% no triênio 2000-2002 contra menos de um terço disso, 14,3\%, no quatriênio anterior. Entretanto, a diferença entre o aumento das IES públicas em relação às privadas é brutal e altamente reveladora da políticas públicas adotadas nesse governo: no triênio 20002002 as IES públicas crescem exíguos 1,5\% e as IES privadas, 59,3\% ou cerca de 40 vezes mais! (SILVA JÚNIOR, SGUISSARDI, 2012)

No início da gestão de Lula, a turbulência econômica e os ruídos da mudança de governo colocou no centro das atenções da administração petista as políticas econômicas, sendo que o crescimento das instituições em geral sofreu redução de aproximadamente $39 \%$. Contudo, a menor expansão do número de instituições dá-se no final de seu primeiro mandato, com estagnação da taxa de crescimento das instituições públicas, merecendo destaque o sistema federal de educação superior. Novamente aqui, o empresariado esperava programas de incentivo ao setor privado e, em face da difícil situação econômica, o governo discutiu muito a reforma universitária e pouco fez no setor público, centrando sua ênfase na política monetária.

Com base na análise dos dados da Sinopse Estatística da Educação Superior (2011), as matrículas tendem a acompanhar a mesma evolução das instituições. Destaca-se, no entanto, que o crescimento é maior nas instituições públicas e ligeiramente negativo nas universidades privadas. A explicação se deve ao aumento de cursos e ao movimento induzido pelo governo de multiplicação dos campi (SGUISSARDI; SILVA JÚNIOR, 2009).

Isto pode estar demonstrando a previsão de consultores da área que anunciavam ainda em 2007 que "grandes fundos de investimentos e 
capital externo apostam seus dólares nos grandes grupos nacionais, que estão comprando instituições médias, que, por sua vez, incorporam as pequenas" (Gorgulho, 2007, apud Sguissardi, 2008, p. 1004).

No texto de SILVA JÚNIOR e SGUISSARDI (2012) pode-se notar que as mudanças significativas das matrículas em relação às instituições, quanto à expansão neste momento, são as seguintes: "para um decréscimo no total de IES federais de $-10,4 \%$ houve um aumento de $27,6 \%$ do total de matrículas; para um aumento de $12,4 \%$ no total de IES particulares, suas matrículas aumentaram 52,3\%". No caso do sistema federal isso pode ser considerado como o resultado do Plano de Reestruturação e Ampliação das Universidades Federais (REUNI), sendo que as matrículas "tendem a dobrar até 2012 o montante de vagas nas Federais existentes em 2007". Já em relação às IES particulares,

Trata-se provavelmente do fenômeno [...] da compra ou incorporação de IES de pequeno porte por IES de porte médio e destas por grandes redes como Anhanguera, Kroton-Pitágoras, Estácio de Sá e Laureate Inc, entre outras, que contam com apoio maciço de fundos de investimento transnacionais (Sguissardi, 2008, p. 1003). Enfatize-se o fato, que aqui se observa, da redução de 43,9\% nas matrículas das IES comunitárias e filantrópicas num período de apenas três anos e da provável migração dos estudantes destas para as particulares que têm um crescimento exponencial de 52,3\% no subperíodo. (SILVA JÚNIOR; SGUISSARDI, 2012, p. 17)

O processo de mercantilização é parte do processo de mundialização da economia, como veremos adiante. Por esta razão, o quadro que se acaba de delinear revela-se com maior ênfase no setor privado. No universo da educação superior brasileira, "há apenas 10 anos as IES comunitárias e confessionais contavam com 37,4\% do total de matrículas; em 2009 , com apenas 16,9\%". No sistema federal de educação superior a redução é significativamente menor: "de $35,1 \%$ para $26,4 \%$ (as federais: de $18,7 \%$ para $14,7 \%$; as estaduais: de 12,7 para 9,4\%; e as municipais: de 3,7\% para 2,3\%). No sentido inverso ao das IES comunitárias e das confessionais, as particulares passaram de $27, \%$ para $56,7 \%$ !"”. Tal crescimento pode ser explicado por meio da política privatista dos governos nas duas últimas décadas - neste caso, em face da longa vida da ação focal realizada pelo Programa Universidade para Todos (PROUNI). (SILVA JÚNIOR; SGUISSARDI, 2012, p.18)

\section{Expansão do setor federal educação superior.}

Os indicadores relacionados à expansão do número de instituições federais e outros tipos institucionais neste campo alcançam um percentual próximo de 55\%, enquanto suas matrículas cresceram 70\% no período 1999-2009. As Sinopses ainda nos mostram outro lado da expansão, com dados "relativos ao aumento dos corpos docente e técnicoadministrativo, e dos cursos, que reforçam o significado dessa expansão que, como já se verificou, apesar de significativa, situa-se ainda assim muito abaixo da observada no setor das IES particulares $(238,2 \%$ e $345,2 \%$ respectivamente)" (SILVA JÚNIOR; SGUISSARDI, 2012). Esta curva apresenta a mesma característica desde 1995, quando FHC tornou-se o presidente, o que nos permite a comparação entre seus governos e os de Lula.

Nos dois mandatos de FHC o número de instituições e matrículas aumentou, enquanto o número de contratação de docentes e de técnico-administrativos diminuiu. A 
tendência da intensificação do trabalho e da precarização de suas relações põe-se já aí em razão da estrutural mudança do projeto para o país, com a aderência à predominância financeira e a nova função e estrutura do aparelho de Estado e das instituições republicanas.

Embora de forma mais palatável à sociedade, a aderência à predominância financeira se mantém com Lula, o REUNI é criado e, em razão disso, por esta medida compensatória, o trabalho docente é intensificado e precarizado. Assim, se pode explicar, entendemos, esta aparente positividade da política de expansão do ex-presidente Lula.

\section{Tendências da pós-graduação: o PNPG (2011-2020)}

As tendências da pós-graduação brasileira podem ser antevistas por meio de uma breve análise do Plano Nacional para Pós-Graduação (2011-2020). No país já se pode considerar o Sistema Nacional de Pós-Graduação (SNPG) um ente forte e consolidado, que já vem caminhando há aproximadamente duas décadas em direção à formação e à produção de conhecimento adequado ao novo projeto de país iniciado com FHC. Quatro são as áreas de fundamental importância para o entendimento dos objetivos ora explícitos na análise deste Plano: a avaliação, a certificação em massa, a internacionalização e a indução ao novo fazer científico influenciado pela epistemologia da prática.

Este Plano vem a ser a adoção de uma política de Estado que visa a criação, por meio de políticas públicas na forma de planos e programas com vistas à integração de um Plano Nacional de Desenvolvimento Econômico e Social, interligado a um Programa Nacional de Pós-Graduação, que convoca a universidade e sua estrutura acadêmicocientífica, técnica e pedagógica a contribuir na inglória busca da inserção do Brasil num sistema econômico mundial e competitivo por mercados. $\mathrm{O}$ fato concreto parece residir na transformação do país numa plataforma de produção de valor para o capital financeiro e em um ótimo destino para o investimento externo direto (IED), além de excelente praça bursátil. A outra face deste movimento consiste no novo lugar econômico e social da universidade pública e suas novas funções nestas esferas.

O gráfico abaixo mostra a série do investimento externo direto no Brasil desde 1947 até 2011. Conforme nele se examina, o IED apresenta um significativo crescimento a partir de 1995 durante o primeiro mandato de FHC em razão da reforma do aparelho de Estado, às privatizações, aos processos de fusões e aquisições ocorridos neste período. $\mathrm{O}$ outro lado deste movimento consiste no novo papel social e econômico da universidade pública, especificamente do setor federal de educação superior. 
Investimento Externo Direto no Brasil

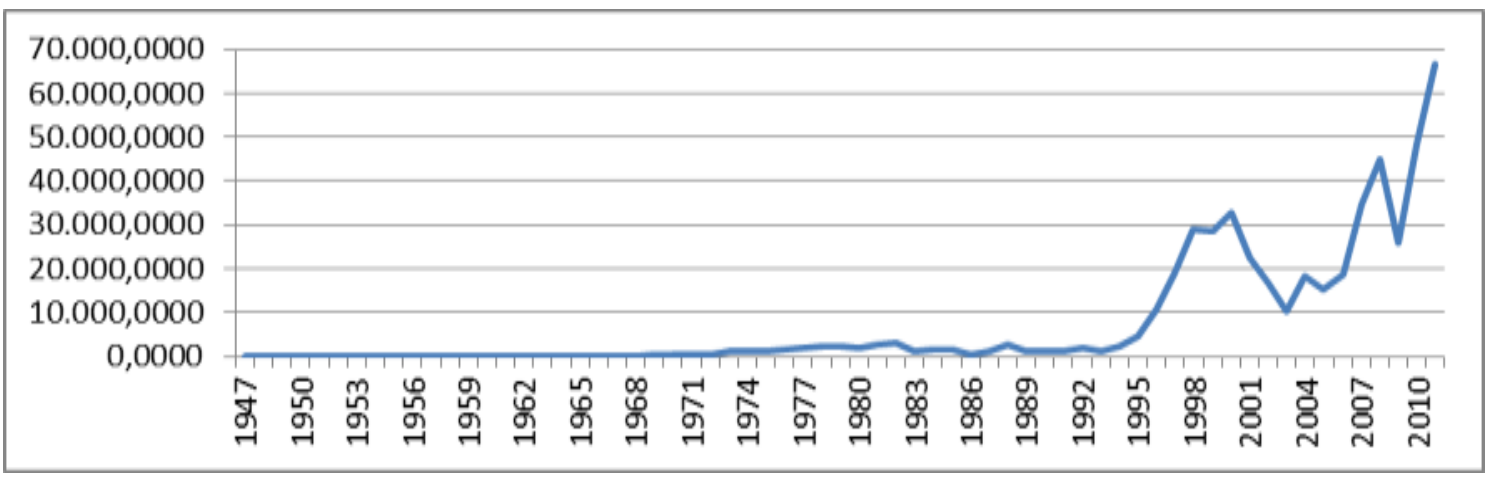

Fonte: IPEA (2012).

Dito de outro modo, a leitura atenta deste plano nos sugere o estabelecimento da relação entre universidade e sociedade com vistas a reorganizar e consolidar o SNPG, buscando a diminuição temporal entre a produção de conhecimento e a sua apropriação pública ou mesmo pela participação das instituições universitárias na formulação e implementação de metas nacionais de desenvolvimento no setor público ou privado. (BRASIL, 2010, p.309).

O social é tratado ao longo do plano como algo que diz respeito diretamente à sociedade; no entanto, quando analisado com minudência, percebe-se que são as relações de produção que estão em pauta, ou mesmo a necessidade de diminuição do fosso entre o nível cultural dos vários segmentos que integram a população brasileira, contrastando com as metas de um país que pretende alçar um melhor posicionamento no mercado mundial de capitais para tornar-se atrativo para o IED. Daí a constante afirmação da importância do envolvimento das universidades e da pós-graduação na construção de políticas públicas, ou mesmo a apropriação, por parte da Coordenação de Aperfeiçoamento do Pessoal de Ensino Superior (CAPES), na realização de parcerias junto ao Ministério da Educação com vistas às políticas de formação de professores.

É possível destacar ainda os programas na área da saúde, pois com o aumento da expectativa de vida é importante manter uma população ativamente produtiva:

Atenção às atuais gerações de crianças e jovens, particularmente nas áreas de saúde e educação em ações voltadas para o ensino básico e superior com a participação da PG, pois dependerá dessas gerações o desempenho da economia brasileira nas próximas décadas, como membros da população em idade ativa, em um contexto de rápido crescimento, em termos absolutos e relativos, e de forte aumento da população idosa. (BRASIL, 2010, p.294)

A pesquisa e a inovação tecnológica são consideradas o centro de todo o programa e o norte de toda mudança da universidade pública, que mobiliza o conjunto dos objetivos em torno do SNPG - daí o papel de destaque à pós-graduação e sua estrutura acadêmicocientífica.

O núcleo da pós-graduação é a pesquisa. A pesquisa depende de treinamento e exige dedicação plena ao estudo, sendo a tarefa das instituições acadêmicas e institutos de pesquisa, públicos ou privados, aliar este e aquela. Os resultados da pesquisa, ao serem aplicados, levam a tecnologias e a procedimentos, podendo ser usados no setor público e no sistema privado, e fazendo do conhecimento e da tecnologia uma 
poderosa ferramenta do desenvolvimento econômico e social. Neste quadro a parceria entre a Universidade, o Estado e as empresas dará lugar ao chamado modelo da tríplice hélice. Este modelo levará a colocar no centro do Plano, ou melhor, na sua base, aquilo que poderá ser chamado de Agenda Nacional de Pesquisa, com a participação de todas as agências de fomento federais e estaduais, com repercussão direta no SNPG e como matéria de políticas públicas, conduzindo a ações induzidas e a parcerias entre as universidades e os setores público e privado. (BRASIL, 2010, p.18, grifo nosso).

Ao partir da avaliação da atual pós-graduação stricto sensu, qualificando-a como de natureza predominantemente acadêmica, voltada à formação de professores e de pesquisadores, e tendo os programas de doutorado no topo do sistema e o mestrado na base, o PNPG (2011-2020) indica a necessidade uma reformulação na natureza e nos objetivos da pós-graduação, criando um sistema de avaliação que se ajuste à diferenciação institucional tão demandada pelo atual sistema produtivo, com objetivos, formas de financiamento e de acesso diferenciados. A observação a ser feita a esse respeito consiste na diferenciação e no enfraquecimento do modelo de universidade humbolditiano, como assim classificam as instituições os formuladores do Plano.

No topo do sistema estão as universidades humboldtianas, conhecidas por patrocinarem a união indissolúvel do ensino e da pesquisa, com a pósgraduação à frente, servindo de modelo ou farol para o sistema. Porém, no primeiro mundo e no Brasil, elas são a minoria, apresentando toda sorte de distorções: trata-se de um conceito ou de um ideal, a exigir ajustes ao ser trazido para os dias de hoje e aplicado à realidade das instituições. Não obstante, elas existem e deverão ser cobradas nas avaliações por sua inserção internacional ou pela capacidade de oferecer cursos de padrão internacional. Ao lado das universidades públicas humboldtianas e de uma ou outra comunitária que integra aquele prestigioso rol, há as públicas não-humboldtianas e as privadas, distinguidas entre as comunitárias e as não-comunitárias, com menos vocação acadêmica e maior proximidade com o mercado e, por vezes, com o setor produtivo. Este conjunto de natureza diferente e complementar deverá responder por demandas e necessidades diferentes: num extremo, a necessidade de formar professores e pesquisadores voltados para o sistema de ensino e de pesquisa; noutro extremo, a necessidade de formar quadros e técnicos altamente especializados para os setores público e privado. Em consequência, será preciso criar mais de um sistema de avaliação e depurar diferentes critérios de teor acadêmico e não-acadêmico, ajustados para as diferentes situações e necessidades, como no mestrado profissional. (BRASIL, 2010, p.128)

É possível observar a indicação de mudanças no sistema de avaliação da pósgraduação que tenham critérios diferenciados, levando em consideração a potencial natureza dos programas: acadêmicos ou aplicados. Mudança desta envergadura exigiria a adoção de outros critérios em face do atual sistema de avaliação da CAPES, vigente a partir de 1997, que recai sobre a combinação de indicadores acadêmicos (produção de livros, papers, dissertações, teses, etc.), baseados em aspectos quantitativos (Brasil, 2011, p.126), não comportando mais a complexidade que a pós-graduação exige, induzindo ao que vários pesquisadores qualificam de Taylorismo intelectual. 
A face da internacionalização enfatiza a interação mais intensa entre instituições brasileiras e internacionais, objetivando fomentar a ampliação do conhecimento científico, sobretudo em áreas menos desenvolvidas do ponto de vista tecnológico e da inovação. A CAPES e o Conselho Nacional para o Desenvolvimento Científico e Tecnológico (CNPq) vêm atuando em parceria, através da colaboração e da mobilidade internacional de pesquisadores inseridos em projetos comuns, na mobilidade de pesquisadores, nas parcerias entre laboratórios virtuais e laboratórios internacionais associados e em pesquisas por meio de parcerias entre investigadores brasileiros, norte-americanos e europeus. (BRASIL, 2010, p.239)

A internacionalização via cooperação internacional tem sua maior expressão no programa do governo federal "Ciência sem Fronteiras"11, para promover a consolidação, expansão e internacionalização da ciência, tecnologia e inovação da competitividade brasileira por meio do intercâmbio e da mobilidade internacional entre alunos de graduação e pós-graduação, com bolsas de estudos, com a finalidade de apreender, por meio da formação acadêmica e técnica, de parcerias e de intercâmbios institucionais, a tecnologia de sistemas educacionais e de pesquisas mais competitivos em países avançados no fomento ao trinômio $\mathrm{C} \& \mathrm{~T} \& \mathrm{I}$ nas áreas consideradas prioritárias e estratégicas para o desenvolvimento econômico do país. (BRASIL, 2011). Há que se lembrar, quanto a esta estratégia, que os países parceiros nos impõem o novo modo de fazer científico e, também, absorvem o que temos de melhor - e, em geral, financiado pelo fundo público.

Estas palavras sintetizam como a pós-graduação deverá se desenvolver nos próximos dez anos ou mais. Em acréscimo, destaca-se que a pós-graduação tornou-se o polo irradiador para as mudanças da universidade pública atual, que se encontra centrada na mercantilização internacionalizada.

No momento em que redigimos este texto, os docentes e técnicos das universidades federais mostram sua insatisfação com as medidas tomadas sobre tal nível educacional durante os governos de FHC e Lula e da presidente Dilma Rousseff. Os professores se encontram em greve há três meses, enfrentando difícil processo de negociação com o governo federal, que se vale de manobras protelatórias, embora ofereça contrapropostas. $\mathrm{O}$ governo central enfrenta a contradição entre atender a gerência monetária imposta por este regime, em que o capital financeiro é hegemônico, ou atender aos interesses nacionais e não ceder ao servilismo imposto há pouco mais de duas décadas.

\section{Buscando entender a expansão no contexto da mundialização econômica}

Esse movimento de expansão da educação superior, nos termos expostos anteriormente, pode ser explicado não apenas com base no processo econômico, mas também no político e no social. No regime de acumulação com a predominância financeira, o capital monetário parece adquirir autonomia absoluta em relação à produção real do valor (primeiro ciclo de movimentação do capital). Trata-se do ápice do fetichismo da mercadoria. Este arranjo leva a mudanças reais no processo de trabalho, na indústria e na educação, impondo à sociedade a matriz teórica, política e ideológica neoliberal, com seu corolário referente à necessária reforma do aparelho de Estado.

De maneira simples, este regime poderia ser assim explicado: a economia real, produtora de riqueza com base no tempo de trabalho humano, movimenta-se a partir de uma abstração real: uma aposta sem cartas na mão, um jogo no qual tudo começa com um blefe. O início é o investimento em qualquer setor econômico. Importa que o risco seja o menor possível e a possibilidade de lucro real a maior que se possa alcançar. Tal investimento é feito através de capital acionário que, além de aposta, é também 
endividamento. Este investimento ou endividamento movimenta a economia real, que produzirá com base nos recursos naturais e no tempo de trabalho humano, o lucro real, que pagaria a aposta inicial com a folga de um lucro operacional, mas, sobretudo, financeiro.

Não é difícil deduzir como são importantes a ciência e as instituições que a produzem e, notadamente, a educação, com o trabalho dos professores na docência em todos os níveis. No âmbito da produção científica, os professores pesquisadores das universidades públicas têm sua pesquisa pautada de fora da universidade e conforme um fazer científico próximo da economia. Neste movimento a universidade é permeada pelo tempo econômico e não o da produção de conhecimento.

Reside aí a importância da educação e da ciência e a relevância mundial que os eventos destas áreas se revestem. Este movimento, que se realizou especialmente nas duas últimas décadas, produziu mudanças estruturais nas universidades públicas e privadas, alavancando, de forma mercantil e internacionalizada a expansão da educação superior brasileira.

Nesse contexto a educação se torna um espaço social estratégico para a produção do valor, financiada pelo fundo público (sua privatização/mercantilização internacionalizada) e focada na profissionalização, em razão da infinitésima diferença entre ciência, tecnologia e inovações tecnológicas que se elaboram quase em tempo real no mundo todo. A reengenharia - as novas formas de organização e do trabalho - torna-se possível graças às novas bases científicas e tecnológicas agregadas às máquinas e equipamentos e à gestão dos trabalhadores. Segundo Serfati (1998, p. 177), isto possibilita uma "baixa de custo em razão da reorganização dos processos de gestão [que] não deve ser de $15 \%$ a $20 \%$, mas de $80 \%$ a $90 \%$ ". É a este processo que Harvey (1994) chamará de compressão espaço-tempo, possível de entender-se, pois a predominância financeira comprime o ciclo de capitais em funções e, consequentemente, o ciclo de produção real de valor. Neste processo e nesta direção exige-se que o aparelho de Estado e a educação sejam reformados de forma estrutural, ao mesmo tempo em que, na condição de um serviço produzido pela iniciativa privada, a educação sofra as mesmas consequências dos demais processos produtores de valor. Ademais, num ambiente de globalização financeira, $o$ Estado coloca títulos de dívida pública também no mercado internacional, tornando a educação, mesmo quando patrocinada pelo Estado, refém indireta dos ditames do mercado financeiro.

\section{Capital financeiro, Reforma do Estado e a expansão da educação superior no Brasil}

Numa espécie de ante-sala da consolidação do regime de acumulação com predominância da valorização financeira, a década de 1990 assistiu, especialmente em seu início, ao processo de mundialização do IED, que experimenta então significativo aumento. No entanto, para além dos aspectos quantitativos do IED na economia mundial, são seus aspectos qualitativos os que mais nos interessam aqui. Para Chesnais (1996), citando Henri Bourguinat, são quatro as principais razões desse movimento:

Em primeiro lugar, diferentemente do comércio exterior, o IED "não tem uma natureza de liquidez imediata [...] ou diferida [...]". Não se reduz a uma transação pontual. Pelo contrário, sua segunda característica é introduzir uma "dimensão intertemporal" de grande importância, pois a "decisão de implantação dá origem a fluxos (produção, comércio, repatriação de lucros) que se estendem, necessariamente, por vários 
longos períodos". A terceira particularidade é "implicar transferências de direitos patrimoniais e, portanto, de poder econômico, sem medida comum à simples exportação". "Por último", diz Bourguinat, "existe um componente estratégico evidente na decisão de investimento da companhia. Não somente seu horizonte é sensivelmente mais amplo, como também as motivações subjacentes são muito mais ricas [...] a ideia de penetração, seja para depois esvaziar os concorrentes locais, seja para 'sugar' as tecnologias locais, [e a produção de conhecimento em lugares que extrapolam a sede do grupo industrial] faz parte desse aspecto 'estratégico' do investimento direto e, geralmente, está inserido num processo complexo de tentar antecipar as ações e reações dos concorrentes". (Chesnais, 1996, p. 54, grifos do autor em itálico e nossos em negrito).

A predominância financeira afeta as relações entre os ciclos de movimentação do capital, impondo formas diversas de organização e introdução de grupos predominantemente industriais (GPIs) ${ }^{12}$ em novo lugar na economia mundial. A função financeira coloca-se como a função que exige maior produtividade e novas formas de organização do trabalho, com consequências para a intensificação do trabalho humano e de precarização das relações de trabalho em qualquer processo com potência de produção de valor, exigindo do trabalhador um novo equilíbrio psicofísico, o que lhe impõe um novo tipo de sociabilidade. Inclui-se aí, portanto, a esfera educacional quando ofertada por instituições privadas. A predominância financeira vai impor ao Estado a produção de um ordenamento jurídico e de políticas públicas sob a mesma orientação.

Num regime de predominância financeira, o ciclo de movimentação do capital portador de juros é dominante e distinto dos demais ciclos, possuindo dupla dimensão, econômica e jurídica. Tal ciclo comprime os outros, produzindo uma intensa movimentação do capital em funções (circulação de mercadorias) que impõem a intensificação do trabalho no âmbito do ciclo de produção real de valor e em todos os setores que a ele se vinculam (Harvey, 1994).

Nesse contexto de mundialização da economia, tendo como estratégia central a necessidade da produção do capital produtivo mas, sobretudo, as novas formas de obtenção de mais-valia por meio de inovações financeiras, o IED, nos moldes examinados por Chesnais e Bourguinat, emerge como o centro de um novo paradigma de empresa, com novas estruturas corporativas, novas formas organizativas e de gestão, assentadas em nova base produtiva, possibilitadas, nesse último caso, pelas atuais tecnologias produzidas no âmbito da terceira revolução tecnológica. Portanto, impõe ao Estado o desenho de políticas para pesquisa e formação de mão de obra nas universidades, tarefa hercúlea depois da adesão brasileira aos imperativos da acumulação financeira desde pelo menos o início da década de 1990. ${ }^{13}$ Afirma Chesnais (1996) que há a emergência de um novo estilo de empresa, em cujo centro encontra-se a estratégia tecnofinanceira realizada pelos Caixas Centralizados dos grupos predominantemente industriais, tendo como base privilegiada o capital humano desses grupos. Essas corporações mundiais teriam em seu centro identitário a natureza e a forma das relações que estabelecem com outras empresas e instituições na esfera econômica e social e com as instituições republicanas, mediadas pelo Estado.

Este movimento produzirá profundos processos de mudanças na esfera educacional, particularmente na educação superior. Assim, a expansão nesse domínio e sua respectiva cultura institucional são afetadas pela mundialização e financeirização do processo de acumulação de capital, implicando mudanças nos princípios expressos em seus pressupostos formativos. Observa-se, no caso da educação superior, que sua especificidade 
tomou a forma de um processo direcionado a uma formação humana reducionista, predominantemente profissionalizante, realizada através de uma lógica voltada ao mercado e privatista (ou mercantilizada).

A materialização desse processo no país se concretiza no início dos anos 1990, quando Fernando Henrique Cardoso assume cargos relevantes no aparelho de Estado.

Paulani e Oliveira (2007), ao tratarem das relações entre centro e periferia da economia mundial, esclarecem o novo lugar e o estatuto do Estado brasileiro:

O conceito de periferia depende da existência do Estado-Nação. Mas a Nação quase desapareceu. Só o Estado permanece intacto como instrumento para governar a força de trabalho e, simultaneamente, relegar os seus direitos a um plano secundário, justificando o aumento da taxa de exploração. Inversamente, esse mesmo Estado vai conceder isenções, subsídios e incentivos com o objetivo de aumentar a lucratividade do capital. Mas a constante necessidade de atrair o capital mundializado [na sua principal forma, o IED] é apenas um lado da globalização. Seu outro lado transforma o Estado em um instrumento de produção e valorização do capital financeiro. (Paulani; Oliveira. 2007, p.15-16; tradução dos autores do original em inglês).

Consequentemente, a reforma do aparelho estatal, iniciada no Brasil em 1995, carrega consigo esta racionalidade, cuja matriz já foi aqui referida, trazida pela predominância financeira. Tem-se origem um novo paradigma, em que as políticas se orientam pela mesma matriz teórica, política e ideológica do Estado já reformado. Esta concepção embasou as reformas das demais instituições republicanas, especificamente, no caso em tela, a reforma da educação superior brasileira. Aqui se busca justificar que se tomou como campo privilegiado de análise o subsistema federal de educação superior por ser ele o setor educacional público institucionalmente mais próximo (e suscetível) às políticas derivadas de um Estado que se tornou instrumento de produção num país cuja nação se desnacionalizou. Contudo, ainda que com mediações, dadas as alterações ocorridas na CAPES, no CNPq e na Financiadora de Estudos e Projetos - FINEP, tais mudanças tendem a se realizar na universidade pública brasileira como um todo.

\section{Conclusão}

O exame das razões que levaram à recente expansão da educação superior no Brasil constitui-se em notório desafio. Debater a questão educacional tomando como referência as especificidades do capitalismo brasileiro manifestas, entre outros fatores, nas disparidades sociais e inclusive regionais, propicia base para uma análise crítica do processo em curso, em especial quanto à certificação em massa na modalidade institucional de Institutos Federais de Educação, Ciência e Tecnologia (IFET).

As cisões educacionais apontadas neste texto acabam por referendar uma divisão de classes bastante rígida no que se refere à formação na educação superior, que poderia assim ser caracterizada: às classes dominantes, uma educação voltada à pesquisa aplicada $\mathrm{e}$ ao saber científico; às classes subalternas, uma educação de cunho profissional, atendendo às demandas imediatas do mercado de trabalho. Particularmente quanto à formação dos trabalhadores, a certificação acaba por exemplificar iniciativas para tal fim. O Programa Universidade para Todos (ProUni), o REUNI, os mestrados e doutorados profissionalizantes, o Programa de Financiamento Estudantil (FIES) para este tipo de pós- 
graduação, a tentativa de transferir a educação superior para o âmbito do Ministério da Ciência e Tecnologia (MCT), atendem às recomendações de organismos internacionais e às reivindicações empresariais quanto à qualificação de trabalhadores para o exercício de suas funções em um cenário de constantes transformações tecnológicas na produção industrial, motivadas pela mercantilização do conhecimento e pela busca do aumento das inovações e dos ganhos financeiros.

As políticas compensatórias ganharam ênfase, legitimadas pelo alto índice de analfabetos funcionais e pela escolaridade brasileira historicamente baixa. Utiliza-se a qualificação profissional como mecanismo para responder aos anseios de inclusão social dos trabalhadores. $\mathrm{O}$ entendimento do desemprego como um processo conjuntural (e não estrutural) legitimou discursos com aparência transformadora, mas cuja essência é profundamente conservadora. Essa política compensatória coloca indagações básicas, envolvendo a efetividade do entendimento do desemprego como um fenômeno conjuntural: tais políticas conseguirão enfrentar os aspectos estruturais do desemprego através da qualificação profissional e da evolução das condições gerais de produção real do valor? Como equacionar a precarização da formação e do exercício da profissão dos professores na educação superior?

Em suma, tudo indica que o capital mundializado e financeirizado submeteu uma economia semiperiférica como a brasileira, mas de grande potencial interno de acumulação e, portanto, de atrativo interesse econômico, aos seus próprios imperativos. Neste movimento transformou a política, no sentido mais preciso do termo, em atividade puramente econômica. A educação superior, como espaço estratégico da construção social, não haveria de ficar incólume aos desdobramentos deste processo.

\section{Referências}

BRASIL. Ministério da Educação. Coordenação de Aperfeiçoamento de Pessoal de Nível Superior. Plano Nacional de Pós-Graduação - PNPG (2011-2020). Brasília, DF: CAPES, 2 v. $\operatorname{dez} 2010$.

BRASIL. Ministério da Educação. Coordenação do Aperfeiçoamento de Pessoal de Nível Superior. Cadernos de Indicadores. Brasília: MEC/CAPES < http://geocapes.capes.gov.br/geocapesds/\#> Acesso: 12/10/2011.

BRASIL. Ministério da Educação. Instituto Nacional de Estudos e Pesquisas Educacionais Anísio Teixeira. Sinopses estatísticas da educação superior. Brasília: MEC/INEP < http://portal.inep.gov.br/superior-censosuperior-sinopse> Acesso: 12/10/2011.

CHESNAIS, François. A mundialização do capital. São Paulo: Xamã, 1996.

CHESNAIS, François. Introdução. In: CHESNAIS, F. (org.) A Mundialização Financeira - Gênese, Custos e Riscos. São Paulo: Xamã, 1998.

CHESNAIS, François. O Capital Portador de Juros; acumulação, internacionalização, efeitos econômicos e políticos. In: CHESNAIS, F. (org.). A Finança Mundializada. São Paulo, Boitempo, 2005.

GÜRÜZ, Kemal (2011). Higher education and international student mobility in the global knowledge economy. Albany: State University of New York Press.

HARVEY, David. Condição pós-moderna. Rio de Janeiro: Edições Loyola, 1994. 
IPEA. Instituto de Pesquisas Econômicas Aplicadas. Séries Investimentos Diretos Estrangeiros no país, anual de 1947 até

2011.Brasília:IPEA<http://www.ipeadata.gov.br>Acesso:28/08/2012.

LINDLOF, T. R., \& Taylor, B. C. (2002). Qualitative Communication Research Methods, 2nd Edition. Thousand Oaks, CA: Sage.

MELO, Marcus et al.. State capacity and institutional change: a case study of telecom regulation in Brazil. http://bresserpereira.org.br/recipient3.asp?cat=103. Access in September 21, 2012.

NEWMAN, F. and COUTURIER, L.. The new competitive arena: markets forces invade the academy. The Futures Project. 2001

PAULANI, Leda; OLIVEIRA. Francisco. Financialization and barbarism: a Perspective from Brazil. In: BOWLES, P. et al. National perspectives on globalization. Hamshire: Palgrave-Macmillian, 2007.

SERFATI, Claude. O papel dos grupos predominantemente industriais na financeirização da economia. In: CHESNAIS, F. A Mundialização Financeira-Gênese, Custos e Riscos. São Paulo: Xamã, 1998. p. 141-181.

SGUISSARDI, Valdemar. Modelo de Expansão da Educação Superior no Brasil: predomínio privado/mercantil e desafios para a regulação e a formação universitária. Educação \& Sociedade. Campinas: CEDES, v. 29, n. 105, p. 991-1022, 2008.

SGUISSARDI, Valdemar; SILVA JÚNIOR, João dos Reis. Trabalho Intensificado nas Federais - pós-graduação e produtivismo acadêmico. São Paulo: Xamã, 2009.

SILVA JÚNIOR, João dos Reis; SGUISSARDI, Valdemar. Formas e Razões da Expansão da Educação Superior no Brasil. In: MANCEBO, Deise; JACOB, Vera; BITTAR, Mariluce. A expansão da educação superior pós-LDB. Maringá: EDUEM, 2012. p. 7-33.

Stiglitz, Joseph. Globalization and its Discontents (2002) X Congreso Internacional del CLAD sobre la Reforma del Estado y de la Administración Pública, Santiago, Chile, 18 21 Oct. 2005.

Swyngedouw, E. "Nem global nem local:" glocalização "ea política de escala." Em Espaços de Globalização: Reafirmando o poder do local , ed. Cox, K, 137 166. New York / London: Guilford / Longman, 1997.

TAVARES, Maria da Conceição. Da fronda ao front. Entrevista. São Paulo, Boitempo Editorial. Revista Praga,n. 2, p. junho de 1997.

United Nations Statistics Division - UNSD (2012).

http://en.wikipedia.org/wiki/United_Nations_Statistics_Division. Access in September 20, 2012.

WALDAVSKY, Bem. The great brain race: how the global universities reshaping the world. New Jersey: Princeton University Press, 2010. 


\section{Notas:}

* Prof. Dr. João dos Reis Silva Júnior. Professor Associado da Universidade Federal de São Carlos, LivreDocente em Educação pela USP e Senior Research Fellow at the Brazil Institute at Mercer University (USA).

${ }^{* *}$ Dr. Eric Spears. Director of International Programs / BRIM - The Brazil Institute at Mercer Assistant Professor of Geography at Mercer University

*** Qualquer discussão relativa à mobilidade acadêmica global deve ser entendida no contexto da crise financeira mundial" (Tradução livre dos autores)

${ }^{1}$ O milagre econômico brasileiro é uma definição dada a um momento de crescimento econômico notável, durante os anos 1970 do regime militar. O crescimento econômico também foi combinado com o crescimento urbano exponencial e da pobreza.

${ }^{2}$ A economia política global moderna foi moldada pelo fim do Sistema de Bretton Woods, em 1972, que permitiu aos membros do FMI escolherem o regime de câmbio, não atrelando sua moeda ao ouro. O câmbio podia flutuar livremente, as moedas das economias nacionais poderiam associar-se a um outro conjunto de moedas, e os membros poderiam adotar moeda de outro país como sua própria moeda (por exemplo, como fez o Equador), e aos estados políticos foi dada a opção de formarem cooperativas monetárias (Fonte: FMI http://www.imf.org/external/about/histend.htm). O dólar estadunidense tornou-se a moeda dominante na economia global.

${ }^{3}$ Uma vez que a economia global teve pouco impacto direto na universidade pública, pode-se afirmar que a reestruturação da economia nacional e a hiperinflação afetaram os gastos orçamentários das universidades com novas admissões. Indiscutivelmente houve maior influência da academia, nos primeiros anos da ditadura militar, quando a mídia era controlada pelo Estado e a política de esquerda estabeleceu raízes fora dos campi universitários.

${ }^{4}$ O Bolsa Família é criticado por não resolver os problemas estruturais da pobreza, mas em vez disso é rotulado como uma forma de política clientelista que acomoda pessoas de baixa renda. Ele é criticado por conservadores, progressistas, e da Igreja Católica por ignorar 500 anos de luta de classes e de racismo fornecendo apenas um alívio temporário e limitado. Aproximadamente 12 milhões de pessoas são beneficiários do Bolsa Família, o que torna este um dos maiores programas sociais do mundo.

${ }^{5}$ Os detalhes de cada período serão apresentados adiante.

${ }^{6}$ O Plano Real foi lançado em 1994 e é reconhecido como o mais bem sucedido plano econômico brasileiro para combater a três décadas de inflação crônica. O plano foi implementado em etapas e introduziu uma nova moeda, o real, em 01 de julho de 1994 (http://www.fazenda.gov.br/portugues/real/planreal.asp).

${ }^{7}$ O presidente Fernando Collor de Mello renunciou em meio a um polêmico processo de impeachment que estava iminente em 1992. Ele foi acusado de corrupção.

${ }^{8}$ Veja BRASIL. Banco Nacional de Desenvolvimento Econômico e Social (BNDES). Privatização no Brasil 1990-1994

$e$

1995-2002.

http://www.bndes.gov.br/SiteBNDES/export/sites/default/bndes_en/Galerias/Download/studies/priv_brazil.p df. Acesso em 27 agosto de 2012.

${ }^{9}$ A Lei 11. 079, promulgada em 30 de Dezembro de 2004, estabelece as normas gerais de direito públicoprivada propostas e contratos de parceria na administração pública no âmbito do Governo Federal, Estados, Distrito Federal e Municípios. Esta lei aplica-se às entidades da administração pública, fundos especiais, agências, fundações públicas direta, as empresas propriedade do Estado, as corporações com capital misto público e privado e outras entidades que sejam controladas, direta ou indiretamente pelo Governo Federal, Estadual, Distrito Federal e Municípios. A parceria público-privada é o contrato de concessão, no patrocinado ou formulários administrativos.

${ }^{10}$ Em reportagem do jornal Folha de S. Paulo (Terceira fase de expansão da rede federal inclui quatro universidades, 47 campi universitários e 208 institutos de educação, ciência e tecnologia), a presidente Dilma Rousseff anunciava que "A interiorização do desenvolvimento econômico e social é o principal norteador da terceira fase de expansão da rede de ensino e pesquisa federal, que deverá abrir 250 mil vagas de ingresso nas universidades federais e de 600 mil matrículas nos institutos federais de educação, ciência e tecnologia, em 2014. Além de democratizar o acesso ao conhecimento, os projetos estão integrados aos 
Arranjos Produtivos Locais e aos grandes investimentos industriais e de infraestrutura, de modo a qualificar profissionais e desenvolver tecnologias necessárias ao progresso com distribuição de renda". http://www.secom.gov.br/sobre-a-secom/nucleo-de-comunicacao-publica/copy of em-questao-1/emquestao-do-dia/novos-polos-de-ensino-vao-desenvolver-regioes-do-pais (Acesso: 17/08/2011).

${ }^{11}$ Em 25/01/2011 o presidente Barack Obama anunciou, em discurso do Estado, a importância da relação bilateral Brasil-EUA. Visitou Brasília e Rio de Janeiro (março de 2011), quando se encontrou com a presidente Dilma Rousseff. Foi nesta visita que o Programa Ciência sem Fronteiras foi comentado como uma área estratégica de desenvolvimento. (Depoimento de Willian L. Gertz, American Institute For Foreign Study, New York, 18.07.2012)

12 Os grupos predominantemente industriais consistem um "conjunto formado por uma sociedade-mãe (chamada de holding do grupo) e as sociedades filiais que estão sob o seu controle. Assim, a sociedade-mãe é acima de tudo um centro de decisão financeira; enquanto as sociedades sob seu controle não passam, na maior parte das vezes, de sociedades exploradoras. O papel essencial de uma sociedade-mãe é a arbitragem permanente das participações financeiras que ela detém, em função da rentabilidade dos capitais envolvidos. É a função de arbitragem da sociedade-mãe que confere ao grupo o seu caráter financeiro." (Morin apud Serfati, 1998, p. 143)

13 Apesar de ter se consolidado na década de 1990, os imperativos da valorização financeira já eram muito fortes por aqui desde meados dos anos 1970.

Recebido em setembro/2012

Aprovado em outubro/2012 